\title{
ANÁLISE FINANCEIRA DA SEGURIDADE E PREVIDÊNCIA SOCIAL NO BRASIL EM TEMPOS DE REFORMAS FISCAIS
}

\author{
FINANCIAL ANALYSIS OF SOCIAL SECURITY IN BRAZIL IN FISCAL \\ REFORM TIMES
}

\author{
LUCIANO HENRIQUE FIALHO BOTELHO \\ Universidade Federal de Viçosa. Endereço: Av. Peter Henry Rolfs, s/n | \\ Campus Universitário | 36570-900 | Viçosa/MG | Brasil. \\ (1) http://orcid.org/0000-0002-9225-1266 \\ luciano.botelho@hotmail.com
}

\section{THIAGO DE MELO TEIXEIRA DA COSTA}

Universidade Federal de Viçosa. Endereço: Av. Peter Henry Rolfs, s/n | Campus Universitário | 36570-900 | Viçosa/MG | Brasil.

Dhttp://orcid.org/0000-0002-0521-3799

costatmt@gmail.com

\section{RESUMO}

Diante das divergentes discussões sobre o equilíbrio financeiro da seguridade social no Brasil, este artigo tem o objetivo de analisar a evolução e confrontação das receitas e despesas do Orçamento da Seguridade Social (OSS) no país, entre 2006 e 2016, com base nas regras de financiamento e ideal social propostos pela Constituição da República Federativa do Brasil de 1988. Ademais, procura-se debater os achados com as finanças públicas nacionais. Na revisão de literatura é abordado o Estado de bem-estar social e a seguridade social, seu custeio e sua relação com os indicadores econômicos e demográficos no Brasil. Metodologicamente, através de uma abordagem predominantemente quantitativa, utilizam-se análises gráficas, documentais, bibliográficas e estatísticas descritivas com dados secundários. Os resultados evidenciam a sustentabilidade financeira da seguridade social e a necessidade do entendimento do custeio tríplice e da unidade no OSS findando a valorização das políticas sociais, em especial a previdência social no regime geral. Fica clara ainda a importância dos cenários econômicos e da influência de outras ações fiscais (desvinculação das receitas da união e desonerações tributárias) no OSS. Conclui-se com a necessidade de uma reestruturação fiscal, com fortalecimento das bases econômicas, e não de reformas estruturais nas políticas sociais no Brasil, uma vez que as contribuições sociais ainda são relevantes para o financiamento do OSS, mesmo sendo necessárias algumas medidas na contenção de despesas.

Palavras-chave: Seguridade Social. Finanças Públicas. Previdência Social. Financiamento.

\begin{abstract}
Given the diverging discussions on the social security financial balance in Brazil, this article aims to analyze the evolution and comparison of revenues and expenses of the Social Security Budget (OSS) in the country, between 2006 and 2016, based on the rules of financing and social ideal proposed by the Federal Constitution of 1988. In addition, it seeks to debate the findings with
\end{abstract}

Artigo apresentado no XLII Encontro da ANPAD - EnANPAD 2018, de 3 de outubro a 6 de outubro de 2018 em Curitiba/PR.

Submissão em 24/08/2019. Revisão em 10/10/2019. Aceito em 06/01/2020. Publicado em 19/02/2020. 
national public finances. The literature review addresses the welfare state and social security, its costing and its relationship with economic and demographic indicators in Brazil. Methodologically, through a predominantly quantitative approach, it uses graphical, documentary, bibliographic and descriptive statistics analyzes with secondary data. The results show the financial sustainability of social security and the need to understand the triple costing and unity in the OSS ending the valuation of social policies, especially social security in the general regime. It is also clear the importance of economic scenarios and the influence of other fiscal actions (Untying of Federal Revenue and Tax Deductions) in the OSS. It is concluded that there is a need for fiscal restructuring, with strengthening of the economic bases, and not for structural reforms in social policies in Brazil, since social contributions are still relevant to the financing of the OSS, even if some measures are needed to contain it of expenses.

Keywords: Social Politics. Public finances. Social Security. Financing.

\section{INTRODUÇÃO}

Adveio ao Brasil, com a Constituição da República Federativa do Brasil de 1988 (CF/88), o fortalecimento do ideal de cidadania e de proteção social, corroborados pela atuação estatal e da sociedade no financiamento das políticas sociais, com destaque para a seguridade social (Constituição da República Federativa do Brasil, 1988). A proteção social se tornou foco quando a CF/88 propôs a construção de um Estado de bem-estar social (Kerstenetzky, 2012). O Estado de bem-estar social consiste, de acordo com Esping-Andersen (1990), na responsabilidade do Estado no suprimento das necessidades fundamentais da sociedade, com fornecimento de renda mínima, saúde, alimentação, moradia, assistência social, previdência social e educação.

No Brasil o bem-estar social foi apropriado na $\mathrm{CF} / 88$ pela educação pública universal e pela seguridade social. Conforme Art. 205, a educação foi incluída como direito de todos e dever do Estado e da sociedade e pelo Art. 194 a seguridade foi determinada: "compreende um conjunto integrado de ações de iniciativa dos Poderes Públicos e da sociedade, destinadas a assegurar os direitos relativos à saúde, à previdência e à assistência social" (Constituição da República Federativa do Brasil, 1988).

Em relação aos estudos acadêmicos sobre a seguridade social, no âmbito da literatura internacional as principais discussões estão fundamentadas em reformas nos sistemas previdenciários, diante da evolução demográfica e de dificuldades fiscais. Tendo em vista o cenário exposto, Polivka e Luo (2015) discutem a dicotomia entre as previdências públicas e privadas nos Estados Unidos da América, corroborada pela evolução neoliberal. Também no âmbito americano, Sass (2015) analisa a relação entre as políticas de previdência e a pobreza entre os idosos. No contexto das reformas, Busquets (2012) debate sobre as alterações nas regras previdenciárias ocorridas na Argentina, Bolívia, Chile e Uruguai, e Wang, Williamson e Cansoy (2016) avaliam os tipos de reformas previdenciárias em países em desenvolvimento. No caso do Brasil, Mendonza (2014) analisou as alterações em relação ao ideal original da previdência social na $\mathrm{CF} / 88$, concluindo que, de forma geral, ainda se mantêm as principais proposições constitucionais, embora vigore um olhar fiscal sobre a seguridade social, que vem deteriorando sua base de financiamento.

As conclusões de Mendonza (2014) caminham paralelas às principais discussões acadêmicas brasileiras sobre a seguridade e previdência social no Brasil. Parte relevante da literatura avalia que existe uma movimentação de diminuição das atividades estatais no âmbito das políticas sociais, vinculadas à diminuição da ampla base de custeio da seguridade social, como argumentam Gentil (2006; 2017), Salvador (2012; 2017), Ibrahim (2015), Vieira e Benevides (2016), Paiva, Mesquita, Jaccoud e Passos (2016) e Fagnani (2017). Ao sintetizar as discussões dos últimos anos que comprometem a manutenção da seguridade social, Fagnani (2017) cita a ampliação das desvinculações de recursos antes vinculados ao Orçamento da Seguridade Social 
(OSS) pela Desvinculação de Receitas da União (DRU), o estabelecimento do Novo Regime Fiscal (EC 95/2016) e a Reforma Previdenciária (PEC 287/2016), que segundo o referido autor contribuíram para "o fim do breve ciclo da cidadania social" no Brasil. Ademais, outros autores apresentam distintas situações que também comprometem a seguridade social, como as desonerações tributárias abordadas por Salvador (2012, 2017) e Ibrahim (2015) e os perdões de dívidas e parcelamento facilitados observados por Gentil (2017). Expõe-se, ainda, a nova proposta de reforma da previdência PEC 06/2019.

Há, entretanto, outra corrente de pesquisadores favoráveis a muitas das medidas citadas, diante do cenário de recessão econômica, do elevado peso dos gastos sociais para o orçamento público e do avanço demográfico que afeta a seguridade e previdência social no Brasil, a exemplo de Maciel (2013), Tafner, Botelho e Erbisti (2015) e Giambiagi e Além (2016). A maior preocupação em relação ao Regime Geral de Previdência Social (RGPS) está na sua tendência de contínua expansão de gastos (Maciel, 2013; Tafner et al., 2015). Segundo Tafner et al. (2015), em 2012 os gastos previdenciários já representavam 12\% do Produto Interno Bruto (PIB) brasileiro, ainda que a população nacional ainda seja relativamente jovem.

Todas situações apresentadas representam uma tentativa de aliviar os cofres públicos diante das dificuldades fiscais. Contudo, a real situação de equilíbrio financeiro da seguridade e previdência social ainda não apresenta convergências literárias, visualizadas nas referidas discussões. A manutenção do orçamento integral da seguridade social (estabelecido pelo Art. 195 da $\mathrm{CF} / 88$ ), o financiamento tripartite na previdência e a utilização de instrumentos fiscais (DRU e desonerações tributárias) nas receitas da seguridade social são discussões envolvidas no financiamento securitário que culminam no aquecido debate acadêmico no que concerne aos resultados financeiros da previdência e seguridade social no Brasil.

Este estudo, desse modo, se propõe a navegar pelas discussões divergentes e identificar a real situação financeira da seguridade e previdência social no Brasil, sem deixar de analisar brevemente, e sem pretensões de esgotar o tema, questões como as projeções de manutenção da RGPS diante da expansão demográfica e a relação entre os gastos sociais e o orçamento público brasileiro. Todavia, este artigo terá como pano de fundo as determinações constitucionais e os ideais de proteção social associados.

Tem-se, dessa forma, a seguinte questão de pesquisa: sob a ótica constitucional, qual a real situação financeira da seguridade e previdência social no Brasil? O objetivo deste artigo consiste em analisar as evoluções e confrontações das receitas e despesas da seguridade e previdência social no Brasil entre 2006 e 2016. Além disso, pretende-se discutir os aspectos envolvidos nos debates previdenciários e propor sugestões de alterações na previdência social visando a sua manutenção financeira e social. É importante destacar que o período analisado foi de importantes mudanças econômicas, políticas e legais no âmbito do custeio da seguridade social. Essa escolha, além disso, corrobora a continuação dos estudos de Gentil (2006) que analisou as contas da seguridade social entre 1990 e 2005. No tocante a previdência social, este estudo abordará apenas o RGPS.

\section{REVISÃO DE LITERATURA}

\subsection{O Estado de Bem-Estar Social e a Seguridade Social no Brasil}

Diante de elevadas dificuldades humanitárias e sociais, principalmente em decorrência das crises econômicas, a exemplo da grande recessão da década de 1930, e de complexidades políticas resultantes das duas grandes guerras mundiais, originou-se o cenário para o desenvolvimento das primeiras medidas de bem-estar social, na Inglaterra em 1942 com a implementação de modelos de proteção social universais (Marshall, 1967; Esping-Andersen, 1990; Polivka \& Luo, 2015; Hemerijck, 2017).

O Estado de bem-estar social é definido como a garantia de atendimento das necessidades básicas da sociedade pelo Estado, com o estabelecimento de políticas de renda mínima, saúde e 
educação para os cidadãos (Bobbio, Matteucci \& Parquino, 1995). Corroborando, EspingAndersen (1990) conceitua o Estado de bem-estar social no sentido de proteção social e solidariedade na atuação do Estado. Na abordagem de Marshall (1967), evidencia-se também o espírito de solidariedade presente na definição de Estado de bem-estar social, pois para o referido autor o Estado de bem-estar social representa um sistema de ajuda mútua na sociedade, no qual todos cidadãos contribuem e recebem benefícios de proteção social.

Existe ainda uma nova abordagem de Estado de bem-estar social, sendo essa apresentada por Esping-Andersen, Gallie, Hemerijck, \& Myles, J. (2002) e Hemerijck (2017). Os referidos autores argumentam sobre a necessidade de mudanças nos sistemas de bem-estar social diante das variações no mercado de trabalho e da expansão do neoliberalismo. $\mathrm{O}$ foco do novo Estado de bem-estar social está em observar as aplicações estatais em políticas sociais como processos de investimento e não como gasto social, uma vez que transformam os beneficiários em contribuintes que corroboram o desenvolvimento econômico (Hemerijck, 2017).

$\mathrm{A} \mathrm{CF} / 88$ do Brasil foi desenvolvida visando uma mudança de paradigma em relação às políticas sociais, buscando expandir a proteção social e estabelecer justiça social (Vianna, 2011; Ibrahim, 2015). A CF/88, dessa forma, representou a sugestão de um Estado de bem-estar social, a partir das políticas sociais universais, caso da saúde e educação pública (Constituição da República Federativa do Brasil, 1988). A saúde universal consiste em uma política associada a um amplo sistema de proteção social denominado seguridade social, sendo esse formado, de acordo com o Art. 194 da CF/88, pela Saúde, Assistência Social e Previdência Social, antes políticas esparsas e restritivas (Constituição da República Federativa do Brasil, 1988; Teixeira, Souza \& Paim, 2014; Yazbek, 2015). O conceito de seguridade social está alicerçado na proteção social e na cidadania, com a garantia de bem-estar econômico e segurança aos indivíduos (Vianna, 2011).

No âmbito da seguridade social, o Art. 201 da CF/88, apresenta a previdência social como uma política de manutenção econômica dos indivíduos em situação de dificuldades laborativas. Estabeleceu-se, ainda, os regimes previdenciários para os servidores públicos, (RPPSs) e o regime para os trabalhadores privados (RGPS) (Constituição da República Federativa do Brasil, 1988; Silva, 2004; Zanirato, 2003). Outros pontos destacados pelo texto constitucional se referem à determinação do sistema de repartição simples para a previdência social, no qual os contribuintes contemporâneos financiam os recebimentos dos beneficiários atuais, a obrigatoriedade de filiação ao sistema previdenciário (Art. 201) e a função tripartite (Estado, trabalhadores e empregadores) no custeio previdenciário, conforme Art. 195.

Tornou-se, ainda, responsabilidade do Estado, a partir da CF/88, a execução de políticas de assistência social. Desse modo, antes do texto constitucional existia, segundo Yazbek (2015), principalmente no período militar, um "Estado de Mal-Estar Social", no qual o clientelismo estava envolto com as questões da assistência social. As mudanças demandadas pela sociedade somente chegaram com a CF/88, estabelecendo, no seu Art. 203, que a assistência social será prestada a qualquer cidadão que necessitar de auxílio. Na contemporaneidade, no entanto, vigoram políticas focalizadas e restritas ao combate à pobreza, assistindo apenas aos excluídos das relações econômicas. Ainda, o subfinanciamento e a falta de interesse social também afetam as políticas de assistência social (Yazbek, 2015).

As três políticas públicas da seguridade social, previdência, assistência e saúde, tiveram uma mudança de paradigma a partir da $\mathrm{CF} / 88$, e a saúde foi a área que mais se desenvolveu. Fortemente debatida e planejada durante o movimento pela Reforma Sanitária Brasileira (RSB), na oitava Conferência Nacional de Saúde em 1986, a saúde foi estabelecida como uma política universal no Brasil, se tornando um direito de todos e obrigação do Estado, considerada como uma grande conquista da sociedade (Teixeira et al., 2014). Nesse escopo, os referidos autores apontam que foi aprovado no congresso federal em 1990 a criação do Sistema Único de Saúde (SUS) como uma política de Estado, pregando a universalidade, igualdade e integralidade à atenção na saúde, através do atendimento descentralizado e com participação social nas decisões de gestão. Assim como na assistência, contudo, a saúde pública através dos SUS enfrenta dificuldades no contexto 
atual. De acordo com Almeida-Filho, Paim e Silva (2014), o SUS se depara com gargalos no que concerne às disputas políticas e ideológicas, no que tange a um serviço universal, sendo vigente insuficiência financeira e falta de mobilização social, no escopo de uma gestão eficiente.

\subsection{Financiamento da Seguridade Social, Demografia e Contexto Econômico}

Ao propor um novo horizonte às políticas sociais no Brasil, em 1988, os constituintes esboçaram uma ampla base de financiamento para a seguridade social, associadas ao estabelecimento de um orçamento único, visando dificultar desvios, e aos princípios de custeio: equidade na forma de participação e custeio, diversidade da base de financiamento e preexistência do custeio em relação ao benefício ou serviço (Constituição da República Federativa do Brasil, 1988). A diversificação das bases de financiamento é visível a partir do Art. 195 da CF/88 e pela Lei Orgânica da Seguridade Social (Lei 8.212/91), sendo o custeio securitário responsabilidade de toda "sociedade, de forma direta e indireta, nos termos da lei, mediante recursos provenientes dos orçamentos da União, dos Estados, do Distrito Federal e dos Municípios, e das (...) contribuições sociais", segundo a lei maior, a partir de contribuições dos empregadores, dos trabalhadores, sobre concursos de prognóstico e com incidência na importação de bens e serviços, além de outras fontes de receita, como destaca a Lei 8.212/91.

O Orçamento Único, ademais, foi estabelecido pelo Art. $195 \S 2^{\circ}$ da CF/88, ressaltando a obrigatoriedade de integração entre saúde, previdência e assistência na construção orçamentária (Constituição da República Federativa do Brasil, 1988). Na Figura 1 estão expostas as fontes de financiamento do orçamento da seguridade social no Brasil, os tributos associados e as respectivas destinações.

\begin{tabular}{|c|c|c|}
\hline $\begin{array}{c}\text { Fontes de } \\
\text { Financiamento }\end{array}$ & Contribuições Sociais/ Receitas & Destinações \\
\hline $\begin{array}{l}\text { Empregador, } \\
\text { empresas } \\
\text { equiparadas. }\end{array}$ & $\begin{array}{l}\text { Contribuição previdenciária patronal, } \\
\text { COFINS, PIS/PASEP, CSLL. }\end{array}$ & $\begin{array}{l}\text { Para a Previdência Social são destinados os } \\
\text { recursos das contribuições patronais, o } \\
\text { PIS/PASEP destinam-se ao Fundo de Amparo } \\
\text { ao Trabalhador e ao Banco Nacional de } \\
\text { Desenvolvimento Econômico e Social } \\
\text { (BNDES). O COFINS e a CSLL são destinados } \\
\text { à seguridade sem locação específica. }\end{array}$ \\
\hline $\begin{array}{lr}\text { Trabalhador } & \text { e } \\
\text { demais } & \\
\text { segurados } & \text { da } \\
\text { previdência. } & \end{array}$ & Contribuição previdenciária do trabalhador. & Locação na Previdência Social. \\
\hline $\begin{array}{l}\text { Concursos de } \\
\text { Prognóstico. }\end{array}$ & $\begin{array}{l}\text { Contribuição para a seguridade social de } \\
\text { parcela dos movimentos globais de apostas. }\end{array}$ & $\begin{array}{l}\begin{array}{l}\text { Destinação não } \\
\text { seguridade social. }\end{array} \\
\end{array}$ \\
\hline $\begin{array}{l}\text { Importação de } \\
\text { Bens e Serviços. }\end{array}$ & $\begin{array}{llll}\begin{array}{l}\text { PIS/PASEP } \\
\text { importação. }\end{array} & \text { importação } & \text { e } & \text { COFINS } \\
\end{array}$ & $\begin{array}{l}\text { Locação semelhante à já mencionada para o } \\
\text { PIS/PASEP e COFINS. }\end{array}$ \\
\hline Outras Receitas & $\begin{array}{l}\text { Cotas particulares das seguintes arrecadações } \\
\text { da União: Prestação de Serviços em Saúde, } \\
\text { Receitas de Taxas, Seguro do Trânsito } \\
\text { (DPVAT), apreensões pela RFB sobre } \\
\text { Atividades Ilegais, Contribuição Sindical e } \\
\text { Contribuições do Sistema "S". }\end{array}$ & $\begin{array}{l}\text { Diversas destinações expostas em leis } \\
\text { específicas. }\end{array}$ \\
\hline
\end{tabular}

Figura 1. Fontes de Financiamento da Seguridade Social conforme CF/88 e Lei 8.212/91

Fonte: Elaborada pelo autor com base na Constituição da República Federativa do Brasil (1988), Lei Orgânica da Seguridade Social (1991) e Ibrahim (2015).

Essa diversificação orçamentária, contudo, vem sendo deteriorada com o passar dos anos no Brasil (Salvador, 2012; 2017; Mendonza, 2014). Um dos principais instrumentos responsáveis por tal situação é a DRU, vigente desde 1994, e que, a partir da EC 93/16, retira do OSS 30\% dos valores arrecadados pelas contribuições sociais: COFINS, Cota-Parte da Contribuição Sindical, Contribuição sobre os Concursos de Prognósticos, PIS/PASEP e CSLL (Ferreira \& Lima, 2016). 
Além da DRU, existem outras atuações fiscais da União que comprometem as receitas do OSS, caso das elevadas desonerações tributárias sobre as contribuições sociais (RFB, 2017). A Receita Federal do Brasil aborda as desonerações tributárias como gastos indiretos do governo, que reduzem a sua arrecadação, através de incentivos, renúncias, anistias, entre outros (RFB, 2017).

A aprovação do Novo Regime Fiscal (EC 95/2016), ademais, consiste em uma medida visando austeridade com os recursos públicos, objetivando, segundo Fagnani (2017), reduzir as despesas primárias federais de 20\% para 12\% do Produto Interno Bruto (PIB), entre 2017 e 2036. Entretanto, para Vieira e Benevides (2016) essa medida reduzirá as aplicações no já enfraquecido cofre da saúde pública no Brasil, implicação que também é verificada por Paiva et al. (2016) para a assistência social.

Tais medidas, estão relacionadas às influências das forças políticas no orçamento público. Na visão de Salvador $(2012$, p. 5) "o orçamento público é um espaço de luta política, com as diferentes forças da sociedade, buscando inserir seus interesses". A partir dos anos 1990, desse modo, no Brasil, verificou-se um fortalecimento político dos ideais de redução da atuação estatal em políticas de proteção social, resultando, conforme apresenta a literatura, em diminuição das atividades do governo nas políticas de seguridade social e no decrescimento dos valores aplicados no OSS, sendo esses revertidos ao orçamento fiscal (Gentil, 2006; Vianna, 2011; Salvador, 2017). Nas visões de Gentil e Maringoni (2008), Mendes e Marques (2009) e Severiano (2016), ademais, visualiza-se no contexto brasileiro a financeirização do Estado, movimento com elevações nas dívidas públicas e foco no mercado financeiro, com desregulamentação e altas taxas de juros, em detrimento do mercado produtivo. Gentil e Maringoni (2008) relatam que, entre 2000 e 2007, os gastos fiscais do governo nacional cresceram 50\%, enquanto os investimentos sociais se elevaram em $35 \%$. Além disso, as dívidas públicas subiram de 29,3\% para 42,8\% do Produto Interno Bruto (PIB) brasileiro.

Nas visões de Matias-Pereira (2010) e Maciel (2013), além do exposto, o Brasil passa por um momento de concentração demográfica da população em idade ativa, pessoas aptas para contribuir com a previdência social. No entanto, existe a tendência de mudança desse cenário: em 2008 existiam 100 crianças para cada 24 idosos; já em 2050 se projeta a relação de 100 crianças para 173 idosos, indivíduos que dependerão dos recursos da seguridade social (Matias-Pereira, 2010). Deveria existir na contemporaneidade uma elevada parcela da sociedade contribuindo para a previdência social. Contudo, Rocha e Macário (2015) e Resende (2001) apresentam que há no Brasil um enfraquecido mercado formal de trabalho, no qual $46 \%$ da população economicamente ativa (PEA) não contribui para essa política.

As flutuações econômicas, além disso, afetam com grande intensidade as arrecadações da seguridade social (Orair \& Aguilar, 2016). As principais contribuições sociais (contribuição patronal previdenciária, CSLL, COFINS e PIS/PASEP) estão diretamente ligadas aos resultados financeiros empresariais. Assim, quando há uma retração econômica, as empresas diminuem seus faturamentos e seus lucros, comprometendo as arrecadações do OSS, sendo também as condições de emprego e desemprego fundamentais para as contribuições do trabalhador e do empregador para a previdência social (Resende, 2001, Tafner et al., 2015; Ibrahim, 2015). Nesse sentido, um pilar para a manutenção de resultados financeiros positivos na seguridade social é o crescimento econômico, uma vez que a este se associam os bons níveis de faturamento, lucro e dimensão das folhas de salários das empresas, principais fontes de custeio da seguridade social (Dieese \& Anfip, 2017).

\section{METODOLOGIA}

Este estudo se utiliza de uma abordagem predominantemente quantitativa de pesquisa. Com relação ao tipo de pesquisa, este é um estudo com maior abrangência descritiva, a qual, segundo Gil (1999), procura apresentar características e fatores relacionados a determinados fenômenos. Quanto aos procedimentos, foram realizadas análises documentais, bibliográficas, 
estatísticas descritivas e gráficas. É importante ressaltar, ainda, que todos os dados monetários foram atualizados a partir do Índice Nacional de Preços ao Consumidor Amplo (IPCA/IBGE 2016).

\subsection{Coleta de Dados e Descrição das Variáveis}

Foram apropriados dados secundários diversos, entre os anos de 2006 e 2016, com origem nas seguintes fontes: Orçamento Federal (Lei Orçamentária Anual - LOA e Projeto de Lei Orçamentária Anual - PLOA), Tesouro Nacional (Relatórios de Execução Orçamentária, Relatório Anual da Dívida Pública - RAD e Plano Anual de Financiamento - PAF) e Receita Federal do Brasil (Relatório de Gastos Tributários). As consultas foram efetuadas nos sites das referidas fontes.

As LOAs foram o principal meio empregado, exceto para os anos de 2006 e 2009, uma vez que nesses anos não foi possível acessá-las, optando-se pelo emprego dos dados disponíveis nos PLOAs. Tal situação provavelmente ocorreu devido a algum equívoco no momento de inserção dos demonstrativos no site Orçamento Federal, o que comprometeu a publicidade dos dados. Ainda, as receitas do RGPS foram coletadas pelos Relatórios de Execução Orçamentária, e diante da atualização das previsões orçamentárias e da maior facilidade de acesso, todas as outras contas tiveram como base a LOA ou a PLOA. As arrecadações das LOAs e dos PLOAs estão disponíveis no demonstrativo denominado "Receita dos Orçamentos Fiscal e da Seguridade Social por Natureza, Fontes de Recursos e Esfera". Já as receitas do RGPS estão presentes no Relatório de Execução Orçamentária no "Demonstrativo das receitas e despesas previdenciárias do regime geral de previdência social".

No âmbito das despesas do orçamento da seguridade social, incluindo as despesas do RGPS, foram coletados os valores disponíveis no quadro "Despesas dos Orçamentos Fiscais e da Seguridade Social por Função Detalhada e Subfunção", presente nas LOAs e nos PLOAs. Os montantes da DRU sobre as contribuições sociais foram coletados no Relatório de Execução Orçamentária no quadro "Demonstrativo das Receitas Desvinculadas por Força de Dispositivo", para todos os anos de estudo. Já os valores das desonerações sobre as contribuições sociais são disponibilizados nos Relatórios de Gastos Tributários da Receita Federal do Brasil.

Todos os valores relacionados às dívidas públicas e pagamentos de juros são dados disponibilizados pelo RAD e PAF apresentados. Os valores colocados como resultados financeiros da seguridade social segundo o Tesouro Nacional, consistem na confrontação entre as receitas e despesas totais do OSS presentes nas LOAs e nos PLOAs. Por fim, os valores apresentados para a Receita Corrente Líquida (RCL) também são disponibilizados pelos Relatórios de Execução Orçamentária do Tesouro Nacional. É importante ressaltar, ainda, que todos os dados sobre a previdência social, receitas e despesas, referem-se ao RGPS.

\subsection{Operacionalização dos Resultados}

Para avaliar a evolução das receitas e despesas do OSS e a confrontação desses últimos, relacionando-os às contas públicas nacionais, foram realizadas análises gráficas temporais, como forma de analisar tendências e evoluções; análises estatísticas descritivas; análises bibliográficas, através das literaturas utilizadas neste estudo e outras publicações; e análises documentais, relacionando os achados às legislações abordadas. Por fim, visando discorrer sobre as perspectivas futuras e necessidades de alterações no contexto financeiro do RGPS, foram utilizadas análises descritivas e bibliográficas, com o auxílio dos estudos da CPIPREV (2017), Dieese; Anfip (2017) e Banco Mundial (2017). 


\section{RESULTADOS E DISCUSSÕES}

\subsection{A Evolução das Receitas e Despesas da Seguridade Social no Brasil}

A CF/88 determinou a criação das contribuições sociais, pelo Art. 195, como principais tributos financiadores do sistema de seguridade social no Brasil. A Tabela 1 expõe as contribuições sociais e as outras receitas, estabelecidas pela Lei 8.212/91, com destinação para a seguridade social e suas evoluções no período em análise.

Tabela 1

Evolução das Contribuições Sociais Destinadas à Seguridade Social por Fonte de Financiamento em Bilhões de Reais

\begin{tabular}{ccccccccc}
\hline Ano & COFINS & PIS/PASEP & CLLS & CPMF & RGPS & $\begin{array}{c}\text { Concurso de } \\
\text { Prognóstico }\end{array}$ & $\begin{array}{c}\text { Outras } \\
\text { Receitas }\end{array}$ & $\begin{array}{c}\text { Receitas } \\
\text { Totais OSS }\end{array}$ \\
\hline $\mathbf{2 0 0 6}$ & 168,011 & 25,286 & 46,329 & 58,745 & 226,512 & 0,143 & 26,741 & 551,767 \\
$\mathbf{2 0 0 7}$ & 179,400 & 27,755 & 54,065 & 63,328 & 238,801 & 1,173 & 30,343 & 594,865 \\
$\mathbf{2 0 0 8}$ & 186,406 & 23,228 & 61,380 & 1,111 & 267,628 & 1,278 & 27,301 & 568,331 \\
$\mathbf{2 0 0 9}$ & 211,286 & 32,694 & 73,982 & - & 298,969 & 1,270 & 33,185 & 651,385 \\
$\mathbf{2 0 1 0}$ & 223,161 & 33,421 & 81,135 & - & 307,762 & 1,297 & 32,761 & 679,537 \\
$\mathbf{2 0 1 1}$ & 217,688 & 33,677 & 85,167 & - & 339,101 & 1,434 & 30,072 & 707,138 \\
$\mathbf{2 0 1 2}$ & 232,956 & 37,172 & 82,311 & - & 366,479 & 2,136 & 34,887 & 755,942 \\
$\mathbf{2 0 1 3}$ & 234,295 & 37,093 & 89,644 & - & 399,538 & 1,901 & 43,175 & 805,646 \\
$\mathbf{2 0 1 4}$ & 237,486 & 39,432 & 78,313 & - & 424,492 & 1,889 & 46,590 & 828,203 \\
$\mathbf{2 0 1 5}$ & 228,569 & 36,528 & 76,104 & - & 421,485 & 1,915 & 39,346 & 803,947 \\
$\mathbf{2 0 1 6}$ & 227,863 & 35,727 & 65,975 & - & 371,930 & 2,215 & 24,803 & 728,513 \\
\hline Variação \% & 35,62 & 41,29 & 42,41 & - & 64,20 & 1450,62 & $-7,25$ & 32,03 \\
$(\mathbf{0 6 - 1 6})$ & & & & & & &
\end{tabular}

Fonte: Dados da Pesquisa, com base em Tesouro Nacional (Execução Orçamentária), Orçamento Federal (LOAs e PLOAs) e Receita Federal do Brasil (Lei de Acesso à informação). Valores atualizados pelo IPCA-IBGE (2016), em bilhões de reais; no que tange ao COFINS, PIS/PASEP, CSLL e CPMF foram desconsiderados os valores da DRU; Concurso de Prognóstico incluiu apenas valores do OSS (Lei 11.345/06); PIS/PASEP 60\% da arrecadação total (vide legislação); não estão presentes valores dos RPPSs, não sendo esses o objeto de estudo. Nas outras receitas estão inclusas: Contribuição Sindical (desconsiderados os valores da DRU); Taxas (Vigilância Sanitária; Saúde Suplementar; TAFIC); Receitas Patrimoniais (Receitas Mobiliária e Imobiliárias); Outras Receitas Correntes (Receitas Diversas; Receitas das dívidas Tributárias; Valores Apreendidos e leilões da RFB; Seguro DPVAT); Receitas de Serviço (Serviços de Saúde; Financeiros, Comerciais e Outros); Outras Receitas (Transferências Correntes; Receitas Agropecuárias; Receitas Industriais; Receitas de Capital).

O primeiro ponto a se destacar, com base na Tabela 1, é a extinção da Contribuição Provisória sobre a Movimentação ou Transmissão de Valores e de Créditos e Direitos de Natureza Financeira (CPMF), tributo que em 2007 rendeu 63 bilhões de reais aos cofres da seguridade social e que era importante para o custeio dos programas de saúde pública, como argumenta Salvador (2012). Nota-se, ademais, que a datar de 2010, as contribuições sociais PIS/PASEP, COFINS e CSLL, não conseguiram manter as elevações arrecadatórias que vinham sendo efetuadas: enquanto as duas primeiras tiveram crescimento de $6,9 \%$ e $2,1 \%$ respectivamente, a CSLL apresentou decrescimento de $18,7 \%$, de 2010 a 2016. É válido ressaltar que nesse mesmo período foi visível um fortalecimento das políticas de desonerações fiscais pelo governo federal, o que pode estar relacionado a tal situação. Segundo dados da RFB (2017) entre 2010 e 2015 as desonerações sobre contribuições sociais (valores que o governo deixa de arrecadar) se elevaram $44 \%$ (Orair \& Aguilar, 2016).

As contribuições diretas para o RGPS foram as receitas que mais se elevaram no período em análise, passando de 226 bilhões em 2006 para 371 bilhões de reais em 2016, expansão 64\% acima da inflação e arrecadação recorde de 424 bilhões em 2014. Com relação às contribuições sociais totais da seguridade social, foi observado um crescimento de $34 \%$, entre 2006 e 2016, e 
arrecadação recorde também em 2014, de 781 bilhões de reais. A despeito disso, é fundamental na análise das receitas da seguridade social a observância dos cenários econômicos e trabalhistas. Portanto, a arrecadação de 2014 pode se relacionar aos indicadores econômicos favoráveis nesse ano (Baltar, 2016). Por outro lado, as recessões econômicas ocorridas em 2015 e 2016 corroboraram as fortes quedas de arrecadação em todas as contribuições sociais nesse período (Baltar, 2016; Diesse \& Anfip, 2017).

Ainda que o panorama de crise econômica enfraqueça as arrecadações da seguridade social, grande parte das despesas securitárias não são afetadas por tal situação. Isso se exemplifica nos benefícios previdenciários e no pagamento do seguro desemprego, despesa da seguridade social inclusa no orçamento do Ministério do Trabalho, situação evidente na Tabela 2. As despesas previdenciárias cresceram 67\% de 2006 a 2016, com expansão de 6\% entre 2014 e 2016. Apesar das elevações, as despesas previdenciárias expandiram em percentual menor do que as despesas da seguridade social no total, que aumentaram em $69 \%$ no período.

As despesas previdenciárias estão associadas aos pagamentos de benefícios de prestação continuada, sobre os quais a União tem total responsabilidade pelo pagamento, conforme Art. 16 da Lei n ${ }^{\circ}$ 8.212/91 (Lei Orgânica da Seguridade Social, 1991). Contudo, despesas com a saúde e a assistência social são afetadas pela redução nos recursos do OSS, as quais tiveram decrescimento de $4,6 \%$ e 5,4\%, respectivamente, entre 2014 e 2016. Nota-se, ademais, que no período analisado as despesas com assistência social passaram de $6,4 \%$ para $10,6 \%$ e da saúde de $13,3 \%$ para $15,1 \%$ da arrecadação total do OSS demonstrando uma evolução que, entretanto, ainda é incompatível com as necessidades dessas políticas, a considerar o contemporâneo subfinanciamento e ainda os resultados futuros do Novo Regime Fiscal (EC 95/2016) (Paiva et al., 2016; Vieira \& Benevides, 2016). Ainda no âmbito da saúde pública, a $E C n^{\circ} 86 / 2015$ determinou que as aplicações de recursos pela União em prestação de saúde não devem ser inferiores a $15 \%$ da Receita Corrente Líquida (RCL) dos exercícios financeiros anuais (Emenda Constitucional $n^{\circ}$ 86, 2015). Desse modo, a partir da análise dos relatórios de execução orçamentária, verificou-se que essa legislação foi fundamental na expansão dos recursos destinados à saúde, e que anteriormente à EC a base percentual de $15 \%$ da RCL apenas em 2014 havia sido atingida.

Tabela 2

Despesas da Seguridade Social por Função em Bilhões de Reais

\begin{tabular}{cccccccc}
\hline \multirow{2}{*}{ Ano } & $\begin{array}{c}\text { Previdência } \\
\text { Social }\end{array}$ & $\begin{array}{c}\text { Assistência } \\
\text { Social }\end{array}$ & Saúde & Trabalho & $\begin{array}{c}\text { Outras } \\
\text { Despesas }\end{array}$ & $\begin{array}{c}\text { Encargos } \\
\text { e Reservas }\end{array}$ & Total \\
\hline $\mathbf{2 0 0 6}$ & 293,36 & 35,08 & 73,11 & 22,83 & 6,65 & 32,73 & 463,77 \\
$\mathbf{2 0 0 7}$ & 321,33 & 42,98 & 80,43 & 28,62 & 7,25 & 14,10 & 494,69 \\
$\mathbf{2 0 0 8}$ & 333,61 & 47,66 & 80,29 & 33,59 & 9,37 & 17,92 & 522,43 \\
$\mathbf{2 0 0 9}$ & 365,27 & 52,80 & 86,83 & 40,17 & 14,42 & 16,21 & 575,68 \\
$\mathbf{2 0 1 0}$ & 366,25 & 58,35 & 92,65 & 44,50 & 14,11 & 20,00 & 595,87 \\
$\mathbf{2 0 1 1}$ & 391,01 & 59,22 & 100,64 & 43,62 & 16,37 & 18,78 & 629,62 \\
$\mathbf{2 0 1 2}$ & 423,39 & 73,39 & 114,14 & 53,84 & 20,08 & 15,10 & 699,94 \\
$\mathbf{2 0 1 3}$ & 445,09 & 78,29 & 116,59 & 51,80 & 21,33 & 12,02 & 725,11 \\
$\mathbf{2 0 1 4}$ & 461,91 & 81,09 & 116,22 & 51,68 & 20,58 & 14,38 & 745,85 \\
$\mathbf{2 0 1 5}$ & 470,05 & 80,31 & 121,02 & 51,24 & 20,28 & 13,88 & 756,78 \\
$\mathbf{2 0 1 6}$ & 490,48 & 77,35 & 109,87 & 55,56 & 18,36 & 32,84 & 784,45 \\
Variação \% (06-16) & 67,19 & 120,48 & 50,27 & 143,30 & 176,14 & 0,33 & 69,15 \\
\hline
\end{tabular}

Fonte: Dados da Pesquisa, com base em Orçamento Federal (LOAs e PLOAs), de 2006 a 2011 quadro 8A e de 2012 a 2016 quadro 6A. Valores atualizados pelo IPCA-IBGE para 2016, em bilhões de reais. As despesas previdenciárias não incluem os valores dos regimes estatutários (RPPSs); os montantes associados ao Ministério do Trabalho incluem apenas as despesas do OSS; Encargos e reservas compreendem os encargos especiais e reservas de contingência; as despesas de assistência social incluem também a conta de direitos de cidadania e as outras despesas contemplam atividades de atenção básica, assistência hospitalar e ambulatorial e outras vinculadas a diversos órgãos federais. 
Argumenta-se, ademais, sobre complexidades na análise das despesas da seguridade social ao se observar as outras despesas presentes na Tabela 2. Segundo o $\S 5^{\circ}$ do Art. 165 da CF/88 são abrangidos pelo OSS os investimentos em todas as entidades e órgãos vinculados à seguridade social, sejam da administração direta ou indireta, além dos fundos e fundações instituídos e mantidos pelo poder público (Constituição da República Federativa do Brasil, 1988).

Incluíram-se como despesas no OSS, entretanto, múltiplos valores investidos em órgãos estranhos à seguridade social e ao Ministério do Trabalho. Em todos os anos de estudo, diversos setores federais apresentaram despesas de assistência hospitalar e ambulatorial, além de atenção básica vinculada ao OSS. Ademais, investimentos extras no Ministério da Defesa, na Administração Geral e no Ministério da Educação, no qual anualmente $10 \%$ dos montantes aplicados são do OSS, foram exemplos de recursos dispendidos pelo OSS em outras áreas. Portanto, nota-se que recursos arrecadados em função da seguridade social não estão sendo aplicados na sua totalidade no orçamento de financiamento da seguridade social.

O aporte de recursos do OSS em outros Ministérios de origem de custeio no Orçamento Fiscal se expandiu de tal maneira que demandou em 2016 18,4 bilhões de reais, crescimento de $176 \%$ em relação a 2006, maior crescimento percentual em despesas na seguridade social. Outros estudos apresentaram resultados convergentes, entre os quais se destaca o de Salvador (2017), que observou elevações $81,88 \%$ acima da inflação no OSS para "outras funções", valores superiores ao crescimento de 48,94\% das despesas securitárias totais, entre 2008 e 2016.

\subsection{Resultado Financeiro da Seguridade e Previdência Social no Brasil e suas relações com as Finanças Nacionais}

Expõe-se, na Figura 2, a confrontação entre todas as receitas e despesas da seguridade social apresentadas anteriormente neste trabalho, gerando os resultados financeiros da seguridade social entre 2006 e 2016. É válido destacar que na presente figura foram desconsiderados os valores da DRU. Todavia, os outros aspectos (despesas estranhas e desonerações tributárias) estão presentes, afetando os achados.

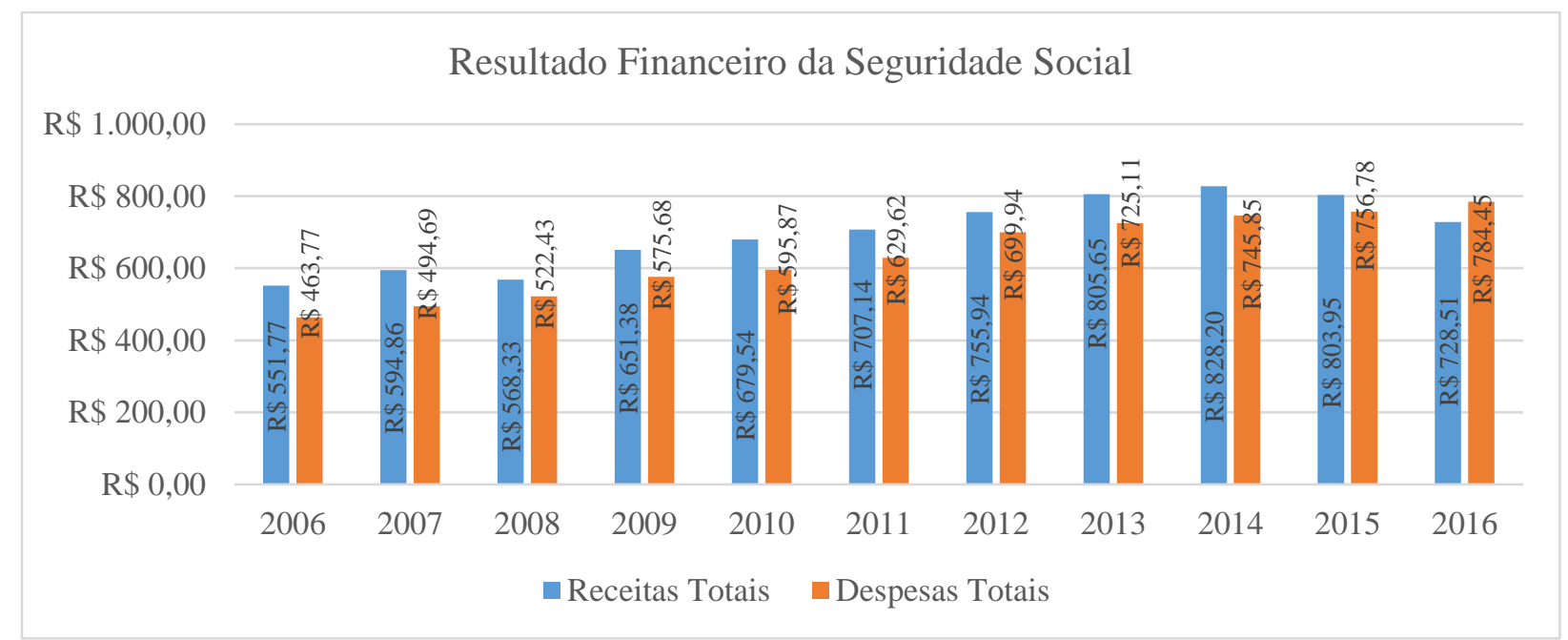

Figura 2. A Evolução do Resultado Financeiro da Seguridade Social no Brasil

Fonte: Dados da pesquisa com consulta ao Tesouro Nacional (Execução Orçamentária), Orçamento Federal (LOAs e PLOAs) e a Lei de Acesso à Informação; Valores atualizados pelo IPCA-IBGE, em Bilhões de Reais.

Evidencia-se, novamente, o efeito dos cenários econômicos na seguridade social: as arrecadações se mantiveram instáveis, de acordo com os contextos trabalhistas e econômicos, e as despesas apresentarem constantes expansões, corroboradas também pelo desenvolvimento demográfico (Dieese \& Anfip, 2017). Desse modo, quando se obtiveram bons resultados 
econômicos a seguridade foi bastante superavitária e mesmo em momentos em que a economia ficou estagnada, ainda assim a seguridade social foi superavitária. Apenas quando o país enfrentou grave recessão econômica essa política apresentou déficit, em 2016. Em média, no período em análise, anualmente a seguridade social foi superavitária em 61,91 bilhões de reais.

Se na análise anterior, ademais, fossem desconsiderados os valores das desonerações tributárias, a seguridade social teria sido superavitária em todos os anos, até mesmo quando enfrentou a grave recessão econômica. Dessa forma, ocorreriam em média anual superávits aproximados de 175,79 bilhões de reais, com resultado positivo de 87,85 bilhões em 2016. Caso fossem descontadas, ainda, as despesas estranhas, o resultado positivo seria de, em média, 191,14 bilhões de reais anuais.

$\mathrm{Na}$ análise do Tesouro Nacional, por outro lado, vigora a DRU, medida que desvinculou 111 bilhões de reais da seguridade social em 2016. Com a inclusão da DRU nos valores da Tabela 1, a seguridade social teria superávits, em média anual, de 5,24 bilhões de 2006 a 2014 e seria deficitária em, 2015 e 2016, em 28,60 e 167,20 bilhões de reais, nessa ordem, diante da grave recessão econômica.

Assim como na análise da seguridade social, a metodologia aplicada pelo Tesouro Nacional na contabilização das receitas e despesas da previdência social se faz pela contabilização bipartite. No entanto, o custeio tríplice foi implementado já em 1923 na lei Eloy Chaves, sendo fortalecido de forma clara e objetiva na CF/34 e na Lei Orgânica da Previdência Social (LOPS), em 1960, e novamente incluído no Art. 195 da CF/88 com a diversidade na base de financiamento da seguridade social e custeio de responsabilidade da União, estados, municípios e Distrito Federal, trabalhadores e empregadores (Zanirato, 2003; Ibrahim, 2015).

Por estar associada à seguridade social e, dessa forma, possuir uma ampla base de financiamento da sociedade e do Estado, a previdência social no Brasil não pode ser vista apenas como uma forma de seguro, como se argumenta, uma vez que na presente política existe o espírito de solidariedade do Estado de bem-estar social e, no âmbito de seu custeio, há a participação do Estado, excluindo, assim, a estreita ligação entre as contribuições e os benefícios, principalmente no contexto de sistema de repartição. Portanto, o Estado deve contribuir a partir das contribuições sociais pagas por toda a sociedade e valores como a COFINS e a CSLL, pertencentes ao OSS, devem adentrar também como receitas da previdência social. Nessa perspectiva, a Tabela 3 expõe as contribuições diretas para o RGPS (empregados e empregadores - bipartite), as despesas totais, o resultado financeiro segundo a metodologia reformista e os recursos passíveis de serem aplicados na previdência social como contribuição do Estado.

Tabela 3

A Evolução do Resultado Financeiro da Previdência Social (RGPS) no Brasil em Bilhões de Reais

\begin{tabular}{lcccc}
\hline Ano & $\begin{array}{c}\text { Contribuições } \\
\text { Diretas }\end{array}$ & Despesas Totais & $\begin{array}{c}\text { Resultado } \\
\text { Contribuições Diretas }\end{array}$ & Disponíveis no OSS \\
\hline $\mathbf{2 0 0 6}$ & 226,51 & 293,36 & $-66,85$ & 214,34 \\
$\mathbf{2 0 0 7}$ & 238,80 & 321,33 & $-82,52$ & 233,46 \\
$\mathbf{2 0 0 8}$ & 267,63 & 333,61 & $-65,98$ & 247,79 \\
$\mathbf{2 0 0 9}$ & 298,97 & 365,27 & $-66,30$ & 285,27 \\
$\mathbf{2 0 1 0}$ & 307,76 & 366,25 & $-58,49$ & 304,30 \\
$\mathbf{2 0 1 1}$ & 339,10 & 391,01 & $-51,91$ & 302,85 \\
$\mathbf{2 0 1 2}$ & 366,48 & 423,39 & $-56,91$ & 315,27 \\
$\mathbf{2 0 1 3}$ & 399,54 & 445,09 & $-45,55$ & 323,94 \\
$\mathbf{2 0 1 4}$ & 424,49 & 461,91 & $-37,42$ & 315,80
\end{tabular}




\begin{tabular}{ccccc}
$\mathbf{2 0 1 5}$ & 421,49 & 470,05 & $-48,56$ & 304,67 \\
$\mathbf{2 0 1 6}$ & 371,93 & 490,48 & $-118,55$ & 293,84 \\
\hline Variação \% (06-16) & 64,20 & 67,19 & 77,34 & 37,10 \\
\hline
\end{tabular}

Fonte: Dados da Pesquisa com consulta ao Tesouro Nacional (Execução Orçamentária) e Orçamento Federal (LOAs e PLOAs); Valores atualizados IPCA-IBGE, em bilhões de reais. Disponíveis no OSS. Inclui Cofins e CSLL desconsiderando a DRU e considerando as desonerações.

Verifica-se, a partir da Tabela 3, que com a utilização, em média anual, de $23 \%$ dos valores arrecadados pela soma da COFINS e da CSLL, se resolvem os 'déficits' apresentados pelo Tesouro Nacional. É interessante destacar, ainda, que a previdência social também é fortemente afetada por desonerações tributárias, e as contribuições para a previdência social são as maiores fontes de desonerações de contribuições sociais. De acordo com dados da RFB (2017), apenas em 2016, 58 bilhões de reais foram desonerados pela previdência social. Além disso, as renúncias se ampliaram 156\% no período estudado: nos anos de 2013, 2014 e 2015 apenas esses valores seriam suficientes para cobrir os 'déficits', presentes na Tabela 3.

Diante da vigência das desonerações sobre as contribuições sociais e da DRU, fica claro o descaso com a seguridade social no orçamento público nacional, sendo realizado um desmonte das suas principais fontes de financiamento. Enquanto o Estado de bem-estar social, no modelo socialdemocrático, proposto na $\mathrm{CF} / 88$, se baseia no aquecimento econômico produtivo, viabilizando o pleno emprego e a contribuição da sociedade através dos tributos para a construção das políticas sociais (Esping-Andersen, 1990; Polivka \& Luo, 2015; Hemerijck, 2017), a financeirização do Estado, alavancada pelo neoliberalismo, se ocupa da desregulamentação financeira, da formação de superávits primários e da valorização da dívida pública, favorecendo o mercado de títulos públicos e rendimentos de aplicadores (Gentil \& Maringoni, 2008; Polivka \& Luo, 2015; Severiano, 2016; Dieese \& Anfip, 2017).

A Tabela 4 demonstra a expansão da dívida pública e do pagamento de juros pelo Estado, além dos discorridos crescimentos da DRU, das desonerações e dos resultados negativos da seguridade social, apontados pelo Tesouro Nacional.

Tabela 4

Endividamento Público, DRU, Desonerações Tributárias e o Resultado do OSS em Bilhões de Reais

\begin{tabular}{cccccccc}
\hline Ano & $\begin{array}{c}\text { Dívida } \\
\text { Externa } \\
\text { (DPFe) }\end{array}$ & $\begin{array}{c}\text { Dívida } \\
\text { Interna } \\
\text { (DPMfi) }\end{array}$ & $\begin{array}{c}\text { Estoque } \\
\text { de } \\
\text { Dívidas }\end{array}$ & $\begin{array}{c}\text { Juros } \\
\text { Pagos } \\
\text { no ano }\end{array}$ & $\begin{array}{c}\text { Resultado } \\
\text { OSS Tesouro } \\
\text { Nacional }\end{array}$ & $\begin{array}{c}\text { DRU S/ } \\
\text { Contrib. } \\
\text { Sociais }\end{array}$ & $\begin{array}{c}\text { Desonerações. } \\
\text { S/ Contrib. } \\
\text { Sociais }\end{array}$ \\
\hline 2006 & 263,32 & $2.006,57$ & $2.269,90$ & - & $-40,83$ & 63,92 & 69,67 \\
2007 & 193,38 & $2.157,29$ & $2.350,67$ & 232,65 & $-47,54$ & 67,18 & 76,94 \\
2008 & 219,37 & $2.093,91$ & $2.313,28$ & 323,15 & $-60,81$ & 61,38 & 82,69 \\
2009 & 157,22 & $2.221,25$ & $2.378,47$ & 179,97 & $-60,39$ & 68,41 & 87,37 \\
2010 & 135,48 & $2.411,78$ & $2.547,27$ & 254,28 & $-60,70$ & 73,35 & 92,29 \\
2011 & 117,45 & $2.514,29$ & $2.622,79$ & 298,24 & $-62,16$ & 73,26 & 97,09 \\
2012 & 121,96 & $2.560,92$ & $2.682,88$ & 277,78 & $-83,40$ & 77,31 & 121,42 \\
2013 & 119,60 & $2.561,93$ & $2.681,53$ & 275,38 & $-64,88$ & 78,96 & 150,89 \\
2014 & 133,13 & $2.721,79$ & $2.854,92$ & 288,43 & $-81,97$ & 78,88 & 166,27 \\
2015 & 153,22 & $2.843,66$ & $2.996,89$ & 394,43 & $-111,29$ & 75,77 & 164,25 \\
2016 & 126,50 & $2.986,50$ & $3.113,00$ & 407,00 & $-220,29$ & 111,34 & 143,79 \\
\hline Variação \% (06-16) & $-51,96$ & 48,84 & 37,14 & 74,94 & 439,55 & 74,17 & 106,38 \\
\hline
\end{tabular}

Fonte: Dados da Pesquisa com base no Tesouro Nacional (Execução Orçamentária, Relatório Anual da Dívida Pública - RAD - e Plano Anual de Financiamento - PAF), Orçamento Federal (LOAs e PLOAs) e Receita Federal do Brasil (Relatório de Gastos Tributários). Valores de atualizações do IPCA-IBGE/2016, em bilhões de reais. 
Verifica-se, no âmbito do orçamento nacional, a expansão da dívida pública nacional, corroborada pelo crescimento em 74,94\% dos valores pagos em juros entre 2006 e 2016, montante que chegou a 407 bilhões de reais em 2016, estabelecendo também a necessidade de manutenção e ampliação da DRU, como ocorreu pela EC 93/2016. No contexto da dívida pública, a Tabela 4 apresenta a confirmação da opção dos governos em priorizar a construção de dívidas no mercado interno (DPMfi), principalmente a partir da emissão de títulos públicos. Na visão de Severiano (2016 p. 680) a expansão da venda de títulos públicos resulta em uma "bola de neve" para o endividamento público, e a União adquire uma das dívidas mais caras no mundo, uma vez que no Brasil se vigora uma elevada taxa básica de juros (SELIC), a qual parametriza a maioria das fontes de endividamento interno (Lopreato, 2008).

Faz-se necessário ressaltar que as despesas nacionais, de 2006 a 2016, sempre se elevaram, sendo dispendidos com a previdência social, a seguridade social e o pagamento de juros da dívida, respectivamente, $14,37 \%, 23,03 \%$ e $10,70 \%$ das despesas totais, em média. Por outro lado, as receitas da União (fiscal e seguridade social) praticamente se mantiveram estagnadas nos anos de estudo, tornando clara a existência de problemas econômicos maiores.

\subsection{Um Olhar Para o Futuro}

Um pilar para a manutenção das políticas de proteção social, como a seguridade social no Brasil, consiste no estabelecimento de uma economia equilibrada. Os aspectos macroeconômicos devem ser incentivados ao desenvolvimento econômico produtivo, pois os fundamentos do Estado de bem-estar social propõem que as suas políticas sejam financiadas por mercados de trabalho aquecidos, formalidade no trabalho e desenvolvimento econômico. A sintonia entre equidade e eficiência no âmbito do Estado de bem-estar social pode proporcionar aos cidadãos dependentes de benefícios fornecidos pelo Estado a inclusão no mercado de consumo, corroborando o desenvolvimento econômico (Esping-Andersen et al., 2002; Hemerijck, 2017). Dessa forma, estudos sobre o Estado de bem-estar social abordam a importância do desenvolvimento econômico para a manutenção das políticas sociais, aspectos visíveis nos achados deste trabalho. Assim, "a crise econômica é que determina as alegadas dificuldades da previdência, e não o contrário. A previdência depende do crescimento econômico e do mercado de trabalho, e não o contrário" (Silva, 2004 p. 29).

Diante do exposto, no aspecto macroeconômico, devem-se pautar medidas para a estabilidade do mercado produtivo e alterações nas legislações tributárias e trabalhistas, findando a redução das complexidades e desigualdades tributárias e maior formalidade no mercado de trabalho. Com relação ao OSS, tendo em vista o olhar social original da CF/88, devem-se cumprir as determinações dos Artigos 194 e 195, integrando-o e mantendo a sua ampla base de financiamento. Além disso, tanto as desonerações sobre as contribuições sociais quanto a desvinculação das receitas da seguridade social são ilegítimas, uma vez que ferem o compartilhamento da responsabilidade de custeio determinada pelo Art. 195, com beneficiamento de alguns setores econômicos e a ampliação das bases de custeio proposta no Art. 195 e na Lei 8.212/91. As desonerações tributárias são medidas que beneficiam grupos específicos e prejudicam os sistemas de concorrência no mercado privado. Já a DRU se utiliza da crítica ao 'engessamento' das fontes de recursos públicos como forma de reduzir a atuação estatal e fortalecer a financeirização. Dessa forma, a DRU deve ser interrompida e as desonerações sobre as contribuições sociais devem ser mais bem estudadas, como também sugeriu o Relatório CPIPREV (2017) e o trabalho da Dieese e Anfip (2017).

No âmbito da previdência social, verifica-se uma forte tentativa de imposição de reformas, com a utilização de estimativas falhas, em relação aos parâmetros econômicos e demográficos, para geração dos resultados projetados para a previdência social no Brasil (CPIPREV, 2017). Além do mais, a literatura reformista se utiliza de comparações equivocadas para afirmar certas "convergências" em relação às reformas na previdência social. Tafner et al. (2015) e outros autores, utilizam-se de comparações entre países para demonstrar o 'problema previdenciário' no 
Brasil. Os referidos autores argumentam que os gastos com a previdência social no Brasil são altos, cerca de $12 \%$ do PIB, sendo essa a mesma taxa da Alemanha, país três vezes mais envelhecido que o Brasil. Todavia, fazer analogia do PIB de um país em desenvolvimento, possuidor de sérios problemas econômicos, com esse indicador econômico de um dos países mais desenvolvimentos do mundo e de maior economia da Europa não faz sentido. Em 2016 o PIB per capita alemão foi de 41.936,10 dólares; já o brasileiro foi de 8.640,90 dólares (Banco Mundial, 2016). Sem levar em consideração, ainda, a diferença na abrangência e qualidade na prestação de outros serviços públicos, que reduzem a dependência da previdência, nesse país.

Além disso, o Índice de Gini (indicador de concentração de renda) dos países mais igualitários é normalmente inferior a 0,30, enquanto o brasileiro é de 0,52. Já o nível de desemprego no Brasil é o dobro da média dos países da Organização para Cooperação e Desenvolvimento Econômico (OCDE) (Dieese \& Anfip, 2017). Portanto, países com níveis de riqueza e de bem-estar social muito superiores aos brasileiros não devem ser parâmetros de comparação para a previdência social. Na visão de Resende (2001), o montante aplicado pelo Estado no âmbito social deve ser baseado nas necessidades humanitárias presentes neste país.

A questão demográfica deve ser alvo de preocupação da sociedade brasileira, não apenas diante da influência na previdência social, mas tendo em vista mudanças também em diversas políticas públicas e na seguridade social como um todo. Do contexto atual até os anos de 2030 e 2040, a pirâmide etária brasileira ainda apresentará concentração da população na melhor idade produtiva, 25 a 50 anos, demonstrando assim que as dificuldades demográficas serão crescentes no Brasil (Matias-Pereira, 2010; Maciel, 2013). Nesse ensejo, o estabelecimento da previdência social no contexto da seguridade social foi a forma encontrada pelos constituintes de 1988 para a manutenção previdenciária a longo prazo, mas, diante do sistema de repartição simples, a evolução demográfica prejudicará a previdência social. Nos anos atuais, contudo, a dificuldade maior para a previdência se encontra em não se aproveitar esse 'momento demográfico positivo' diante do elevado desemprego e da ampla informalidade no mercado de trabalho. Segundo Rocha e Macário (2015), 46\% da população economicamente ativa (PEA) no Brasil não contribui para a previdência social.

A vislumbrada evolução demográfica, ademais, se apresenta como desafio para a sociedade atual, uma vez que serão necessários ajustes em algumas regras previdenciárias, visando a manutenção da previdência social no futuro, sem comprometer as outras funções da seguridade social. Portanto, algumas questões operacionais devem ser debatidas, a exemplo da fixação de uma idade mínima de aposentadoria, como forma de coibir aposentadorias antecipadas, desde que sejam observados casos específicos, principalmente relacionados aos trabalhadores rurais, às profissões que dependem dos esforços físicos, às questões de gênero e às desigualdades regionais (Dieese; Anfip, 2017).

O principal ponto de reforma previdenciária, porém, deve estar na extinção de nichos populacionais privilegiados no âmbito principalmente dos RPPSs, responsáveis por elevadas injustiças sociais, como também apontam Rocha e Macário (2015) e Banco Mundial (2017). Além disso, para perspectivas futuras, pode ser interessante a análise de alterações nas alíquotas de recolhimento de contribuições dos trabalhadores, assunto discutido em vários países e que não é colocado em pauta no Brasil. A recriação do Ministério da Previdência Social, dando a esse órgão maior autonomia na físcalização e gestão do RGPS, também é relevante na busca pela redução da inadimplência previdenciária, das sonegações e das fraudes.

\section{CONSIDERAÇÕES FINAIS}

A partir de uma abordagem própria em relação às receitas e despesas da seguridade social, sob a ótica do financiamento securitário na CF/88 e na Lei 8.212/91, este artigo analisou as receitas, despesas e resultados financeiros da seguridade social no Brasil. Além disso, debateu diversos aspectos envolvidos nas discussões fiscais sobre previdência e seguridade social e suas 
relações com as finanças públicas nacionais, diferenciando-se, assim, de outros trabalhos na área. Os resultados evidenciaram a sustentabilidade financeira da seguridade social, sob o olhar constitucional, e a necessidade do entendimento de custeio tríplice e da unidade no OSS findando a valorização das políticas sociais, em especial, a previdência social. Ademais, ficou claro, para o âmbito da seguridade social, o quanto os cenários econômicos e trabalhistas são relevantes.

Desse modo, identificou-se, sob a ótica constitucional, um cenário complexo no âmbito financeiro da seguridade social. Complexo, no entanto, não tanto pelo grande desequilíbrio que parte da literatura relata, mais sim pelas constantes desvinculações e desonerações de recursos do Orçamento da Seguridade Social.

É preocupante o grande debate fiscal sobre as políticas sociais, que acabam diagnosticando a previdência social como culpada pelas dificuldades fiscais do Estado. Por outro lado, verifica-se a expansão da financeirização do Estado, sendo essa pouco debatida, ao passo que o pagamento de juros pelo governo federal já representa $83 \%$ do que é dispendido com o RGPS. O Brasil necessita de uma reestruturação fiscal, com fortalecimento das estruturas básicas econômicas que propicie maior eficiência aos sistemas tributários e trabalhistas, e não de reformulações estruturais nas políticas sociais. Ademais, há problemas na previdência social que devem ser debatidos e alterações que carecem de ser feitas, desde que não se retirem direitos das parcelas mais necessitadas da sociedade.

Relatou-se, por fim, as dificuldades em agrupar os dados financeiros nacionais e a falta de padronização nos demonstrativos públicos, principalmente em análises temporais, que comprometem a transparência dos dados e a possibilidade de análises aprofundadas. Nesse sentido, este estudo possui como limitação a elevada utilização de dados orçamentários, podendo existir uma lacuna entre o orçado e o executado. Todavia, os orçamentos públicos representam o planejamento econômico e o político dos governos, demonstrando não apenas os valores monetários, mas também seus ideais e prioridades.

\section{REFERÊNCIAS}

Almeida-Filho, N. de, Paim, J. S., \& Silva, L. M. V. da (2014). Saúde Coletiva: futuros possíveis. In J. S. Paim, N. Almeida-Filho (Orgs.). Saúde coletiva: teoria e prática (1a ed., pp. 669-686). Rio de Janeiro: Medbook.

Banco Mundial. (2016). PIB per capita (US\$ a precios actuales). Dates, 2016. Recuperado em 22 novembro, 2017, de https://datos.bancomundial.org/indicador/NY.GDP.PCAP.CD.

Banco Mundial. (2017). Um Ajuste Justo: Análise da eficiência e equidade do gasto público no Brasil. Volume I: Síntese.

Baltar, P. (2015). Crescimento da Economia e mercado de trabalho no Brasil. Brasília. Texto para discussão 2036, IPEA.

Bobbio, N., Matteucci, N., \& Parquino, G. (1995). Dicionário de política. Brasília: UnB.

Busquets, J. M. (2012). Las re-reformas de los sistemas de pensiones en: Argentina, Bolivia, Chile y Uruguay. (2003-2010). Cuarto Congreso Uruguayo de Ciencia Política, "La Ciencia Política desde el Sur", Asociación Uruguaya de Ciencia Política, 14-16.

Comissão Parlamentar de Inquérito do Senado Federal (CPIPREV). (2017). CPI de Previdência Social: Relatório Final. Senado Federal. 
Constituição da República Federativa do Brasil de 1988. (1988). Recuperado em 13 outubro, 2017, de http://www.planalto.gov.br/ccivil_03/constituicao/constituicaocompilado.htm

Departamento Intersindical de Estatística e Estudos Socioeconômicos (DIEESE), \& Associação Nacional dos Auditores Fiscais da Receita Federal do Brasil (ANFIP) (2017). Previdência: reformar para excluir? Contribuição técnica ao debate sobre a reforma da previdência social brasileira. Brasília.

Emenda Constitucional $n^{o}$ 86, de 17 de março de 2015 (2015). Recuperado em 18 maio, 2017, de http://www.planalto.gov.br/ccivil_03/constituicao/Emendas/Emc/emc86.htm\#art1

Esping-Andersen, G. (1990). As três economias políticas do Welfare State. In The theree worlds of welfare capitalism. Princeton, Princeton university press.

Esping-Andersen, G., Gallie, D., Hemerijck, A., \& Myles, J. (2002). Why we need a new welfare state. Oxford University Press, USA.

Fagnani, E. (2017). O fim do breve ciclo da cidadania social no Brasil (1988-2015). Texto para discussão. Unicamp. IE, Campinas, n. 308.

Ferreira, F. G. B. de C., \& Lima, R. A. (2016). A Desvinculação das Receitas da União (DRU) como Instrumento de Flexibilização do Orçamento Público no Brasil: Necessidade ou Distorção? Revista de Direito Financeiro, 2 (2).

Gentil, D. L. (2006). A Política Fiscal e a Falsa Crise da Seguridade Social Brasileira - Análise financeira do período 1990-2005. Tese de Doutorado, UFRJ.

Gentil, D. L. (2017). A previdência social 'paga o preço' do ajuste fiscal e da expansão do poder financeiro. Revista da ABET, 16(1).

Gentil, D. L., \& Maringoni, G. (2008). A Constituição de 1988 e a Seguridade Social: uma disputa em meio à financeirização do Estado. In 20 anos da Constituição Cidadã: Avanças e desafios da seguridade social. ANFIP, Brasília.

Giambiaig, F., \& Além, A. C. (2016). Finanças Públicas: Teoria e Prática no Brasil (5a ed.) Elsevier.

Gil, A. C. (1999). Métodos e Técnicas de Pesquisa Social (5a ed.). São Paulo: Atlas.

Hemerijck, A. (2017). A Revolução silenciosa do paradigma de investimento social na União Europeia. In Políticas e riscos sociais no Brasil e na Europa: convergências e divergências. Editora Hucitec, pp. 25-60.

Ibrahim, F. Z. (2015). Curso de Direito Previdenciário (21a ed.). Rio de Janeiro: Impetus.

Kerstenetzky, C. L. (2012). O Estado de Bem-Estar Social na Idade da Razão: a reinvenção do Estado Social no mundo contemporâneo. Rio de Janeiro: Elsevier.

Lei Orgânica da Seguridade Social, 8.212 de 24 de julho de 1991(1991). Recuperado em 13 outubro, 2017, de http://www.planalto.gov.br/ccivil_03/leis/L8212cons.htm 
Lopreato, F. L. C. (2008). Problemas de gestão da dívida pública brasileira. Texto para Discussão. IE/UNICAMP n. 139.

Maciel, P. J. (2013). Finanças públicas no Brasil: uma abordagem orientada para políticas públicas. Rev. Adm. Pública, 47(5), 1213-241.

Marshall, T. H. (1967). Cidadania, Classe Social e Status (Tradução: Meton Porto Gadelha). Rio de Janeiro: Zahar Editores.

Matias-Pereira, J. (2010). Reforma da previdência em discussão: expectativas e possibilidade diante da janela de oportunidades demográficas. UnB.

Mendes, A, \& Marques, R. M. (2009). O financiamento do SUS sob os "ventos" da financeirização. Ciência e Saúde coletiva, 14(3), 841-850.

Mendonza, G. F. (2014). Brasil: la Constitución de 1988 y las reformas a los sistemas de pensiones. Revista Latinoamericana de Derecho Social, (19).

Orair, R. O., \& Aguilar, D. L. F. de. (2016). Desonerações em alta com rigidez na carga tributária: o que explica o paradoxo do decênio 2005-2014? Economia Aplicada, 20(1).

Orçamento Federal. (2017). Orçamentos anuais. Ministério do Planejamento, orçamento e gestão, secretaria de orçamento federal. Recuperado em 25 novembro, 2017, de http://www.orcamentofederal.gov.br/clientes/portalsof/portalsof/orcamentos-anuais

Paiva, A. B. de, Mesquita, A. C. S., Jaccoud, L., \& Passos, L. (2016). O Novo Regime Fiscal e suas implicações a política de Assistência Social no Brasil. Nota Técnica, n. 27, IPEA. Brasília.

Polivka, L., \& Luo, B. (2015). The Neoliberal Political Economy and Erosion of Retirement Security. The Gerontologist (Oxford), 55(2).

Receita Federal do Brasil (RFB) (2017). Demonstrativo dos Gastos Tributários Ministério da Fazenda do Brasil, 2017. Recuperado em 25 novembro, 2017, de http://idg.receita.fazenda.gov.br/dados/receitadata/renuncia-fiscal

Resende, F. A. (2001). Finanças Públicas (2a ed.). São Paulo: Atlas.

Rocha, F. R. F., \& Macário, E. (2015). Padrão atual de acumulação de capital, mundo do trabalho e reestruturação da previdência social no Brasil. Revista Katálysis, 18(2), 191-201.

Salvador, E. S. (2012). Fundo Público e financiamento das Políticas Sociais no Brasil. Sev. Soc. Rev., 14(2).

Salvador, E. S. (2017). O desmonte do financiamento da seguridade social em contexto de ajuste fiscal. Serv. Soc. Soc., 130, 426-446.

Sass, S. A. (2015). Will social security keep fewer of tomorrow's elderly out of poverty? Center for Retirement Research at Boston College, Number 15-19.

Severiano, E. O. (2016). Tendências e impasses na seguridade social e o futuro da previdência no Brasil contemporâneo. Revista de Políticas Públicas, 20(2), 669-690. 
Silva, A. A. da. A. (2004). Reforma na previdência social brasileira entre o direito social e o mercado. São Paulo em Perspectiva, 18(3), 16-32.

Tafner, P., Botelho, C., \& Erbisti, R. (2015). Debates sobre a previdência: as convergências. In: Reforma da previdência: a visita da velha senhora. Editora Gestão Pública: Brasília.

Teixeira, C. F., Souza, L. E. P. F. de, \& Paim, J. S. (2014). Sistema Único de Saúde (SUS): a difícil construção de um sistema universal na sociedade brasileira. In J. S. Paim, N. \& Almeida-Filho (Orgs.). Saúde coletiva: teoria e prática (pp. 121-138). Rio de Janeiro: Medbook.

Tesouro Nacional. (2017). Relatório Anual da Dívida Pública; Plano Anual de Financiamento; Relatório de Execução Orçamentária. Ministério da Fazenda do Brasil. Recuperado em 25 novembro, 2017, de http://www.tesouro.fazenda.gov.br

Vianna, M. L. T. W. (2011). A americanização (perversa) da seguridade social no Brasil: estratégias de bem-estar e políticas públicas. IUPERJ, Editora Revan.

Vieira, F. S., \& Benevides, R. P. de S. (2016). Os impactos do Novo Regime Fiscal para o financiamento do Sistema Único de Saúde e para a efetivação do direito à saúde no Brasil. Nota Técnica, $n^{\circ} 28$, IPEA. Brasília.

Wang, X., Williamson, J. B., \& Cansoy, M. (2016). Developing countries and systemic pension reforms: Reflections on some emerging problems. International Social Security Review, 69.

Yazbek, M. C. (2015). Políticas Sociais e Assistenciais: Estratégias Contraditórias de Gestão Estatal da Pobreza das Classes Subalternas. In Classes subalternas e assistência social (8a ed.). Cortez Editora.

Zanirato, S. H. (2003). O Descanso do Guerreiro. Editora da Universidade Estadual de Maringá. 